\title{
Stathmin is enriched in the developing corticospinal tract
}

\author{
Heidi R. Fuller ${ }^{1,2,3}$, Robert Slade ${ }^{2,3}$, Nataša Jovanov-Milošević, Mirjana Babicí, Goran \\ Sedmak ${ }^{4}$, Goran Šimić, Matthew A. Fuszard ${ }^{5+}$, Sally L. Shirran ${ }^{5+}$, Catherine H. Botting ${ }^{5}$, Monte
} A. Gates ${ }^{2} *$

${ }^{+}$These authors contributed equally.

${ }^{1}$ Wolfson Centre for Inherited Neuromuscular Disease, RJAH Orthopaedic Hospital, Oswestry, SY10 7AG, UK; ${ }^{2}$ Institute for Science and Technology in Medicine, Keele University, Staffordshire, ST5 5BG, UK; ${ }^{3}$ Postgraduate Medicine, Keele University, Staffordshire, ST5 5BG, UK; ${ }^{4}$ Croatian Institute for Brain Research, Zagreb 10000, Croatia; ${ }^{5}$ BSRC Mass Spectrometry and Proteomics Facility, Biomedical Sciences Research Complex, University of St Andrews, North Haugh, St Andrews, Fife, KY16 9ST, UK

*To whom all correspondence should be sent: Dr. Monte A. Gates, Keele University, Department of Life Sciences, Huxley Building, Staffordshire ST5 5BG, United Kingdom. Ph\# +44-1782733875. e-mail: m.a.gates@ keele.ac.uk 


\begin{abstract}
Understanding the intra- and extracellular proteins involved in the development of the corticospinal tract (CST) may offer insights into how the pathway could be regenerated following traumatic spinal cord injury. Currently, however, little is known about the proteome of the developing corticospinal system. The present study, therefore, has used quantitative proteomics and bioinformatics to detail the protein profile of the rat CST during its formation in the spinal cord. This analysis identified increased expression of 65 proteins during the early ingrowth of corticospinal axons into the spinal cord, and 36 proteins at the period of heightened CST growth. A majority of these proteins were involved in cellular assembly and organisation, with annotations being most highly associated with cytoskeletal organisation, microtubule dynamics, neurite outgrowth, and the formation, polymerisation and quantity of microtubules. In addition, 22 proteins were more highly expressed within the developing CST in comparison to other developing white matter tracts of the spinal cord of age-matched animals. Of these differentially expressed proteins, only one, stathmin 1 (a protein known to be involved in microtubule dynamics), was both highly enriched in the developing CST and relatively sparse in other developing descending and ascending spinal tracts. Immunohistochemical analyses of the developing rat spinal cord and fetal human brain stem confirmed the enriched pattern of stathmin expression along the developing CST, and in vitro growth assays of rat corticospinal neurons showed a reduced length of neurite processes in response to pharmacological perturbation of stathmin activity. Combined, these findings suggest that stathmin activity may modulate axonal growth during development of the corticospinal projection, and reinforces the notion that microtubule dynamics could play an important role in the generation and regeneration of the CST.
\end{abstract}

\title{
Keywords
}

Corticospinal tract, Spinal Cord, Development, Proteomics, Microtubule Dynamics, stathmin 


\section{Abbreviations:}

CNS - central nervous system

CST - corticospinal tract

CRL - crown-rump length

FA - formic acid

FDR - false discovery rate

IPA - ingenuity pathway analysis

iTRAQ - isobaric tag for relative and absolute quantitation

$\mathrm{MeCN}$ - acetonitrile

$\mathrm{P}$ - postnatal day

PBS - phosphate buffered saline

PFA - paraformaldehyde

$\mathrm{RT}$ - room temperature

$\mathrm{SCI}-$ spinal cord injury

TBS - Tris- buffered saline

TEAB - tetraethylammonium bromide

wg - weeks of gestation 


\section{Introduction}

The mammalian corticospinal tract (CST) is the longest efferent axonal projection in the central nervous system (Stanfield, 1992; Sakai and Kaprielian, 2012). Apart from the substantial distance that CST axons must grow, upper motor neurons from layer V of the (mostly primary motor, supplementary motor, premotor and somatosensory, but also widespread regions of the parietal and frontal) cortex extend axons that must navigate a complex route to reach their targets in the anterior horns of the spinal cord. From the cortex, CST axons must first course caudally through the corona radiata and capsula interna to reach the brain stem, where a majority of these axons decussate in the medullary pyramids (Donkelaar et al., 2004). Thick bundles of fasciculated corticospinal axons must then continue a contralateral projection within well defined white matter tracts of the spinal cord until they reach a target segment of the cord, where, after a delay, they mostly synapse with an appropriate interneuron in the ventral grey matter that then synapses with a lower motor neuron.

At the protein level, formation of the CST is achieved via the intracellular responses of growing axons to signals in the extracellular environment. Though the proteins involved in the precise growth of corticospinal axons from the cortex to targets in the spinal cord are not fully understood, it is generally thought that a process of chemoattractive / chemorepulsive signalling (via extracellular proteins) and catastrophe / rescue responses (via intracellular proteins) all play a role. Initially, extracellular expression of semaphorins appear to have both chemoattractive and chemorepulsive properties that facilitate the exiting of corticospinal fibers from the cortex (Bagnard et al., 1998). From here, the expression of netrins may provide an attractive signal in the extracellular environment to facilitate the caudal growth of CST axons into the diencephalon (Richards et al., 1997; Metin et al., 1997). At the medullary pyramids, the absence of inhibitory proteins (or an inhibitory glial barrier), as well as the presence of netrin related proteins, are both thought to allow / facilitate CST axons to cross the midline (Joosten and Gribnau, 1989; Finger et al., 2002). From this point, however, much less is known about how CST neurons navigate their course down the spinal cord itself.

In contrast to human corticospinal neurons (which mostly traverses the lateral CST), the development of a vast majority ( $95 \%)$ of rat CST axons proceeds caudally through the spinal 
cord along the ventral wedge of the dorsal columns. Anatomically, the first axons of the rat CST to enter the spinal cord appear in the upper cervical region at the day of birth. These axons subsequently extend into upper thoracic regions by postnatal day (P) 3, and reach the most distal sacral regions by P9 (Donatelle 1977; Schrayer and Jones, 1982). At the molecular level, the extracellular expression of the protein L1/CAM appears crucial for maintaining the fasciculation of CST fibers as they grow, and to the eventual functioning of the CST. However, L1/CAM is not thought to be involved in stimulating pathfinding of the tract caudally (Dobson et al., 2001). Similarly, the presence of ephrin B3 or B4 ligand-receptor complexes along the spinal cord midline are considered important for maintaining the bilateral segregation of corticospinal axons along the length of the spinal cord (Yokoyama et al., 2001). However, these proteins appear more important for maintaining the laterality of CST axons, rather than actual CST formation (Harel and Strittmatter, 2006).

Little, in fact, is known about the intracellular and extracellular proteins that are important to the growth of corticospinal neurons caudally down the spinal cord. This is unfortunate due to the fact that regeneration of the CST within the spinal cord is of great therapeutic importance. Each year, there are an estimated 6,500 cases of spinal cord injury (SCI) in Western Europe, and between 100,000-200,000 incidences worldwide (Lee et al., 2014). One hope is that by identifying key intracellular and extracellular proteins involved in the development of the corticospinal system, the regeneration of the mature CST might be enhanced by manipulating these developmental constituents.

The aim of this study, therefore, was to conduct a comprehensive quantitative proteomics analysis of the rat CST during its formation. By conducting both a spatial and temporal comparison of the developing CST with the more mature CST and other white matter tracts of the developing spinal cord, we show that stathmin 1 - a major intracellular regulator of microtubule dynamics -is highly enriched in the developing CST . Also, we have shown that manipulating stathmin activity in vitro significantly reduces neurite growth from embryonic rat cortical neurons. Such findings suggest that stathmin may have an important role in the growth of corticospinal neurons during development, and that future work clarifying the function of developmentally regulated proteins in the CST may provide insights into how axonal growth along the spinal cord may be facilitated. 


\section{Materials and methods}

All in vivo procedures were approved by the Animal Welfare \& Ethical Review Body (AWERB) at Keele University, and were carried out under the licensed authority of the UK Home Office. All adult Sprague Dawley rats were housed in a 12-12 h light-dark environment, and given free access to food and water throughout the study.

\subsection{Tissue extraction for mass spectrometry and western blot analysis}

Animals were given an overdose of pentobarbitone anaesthetic (via i.p. injection) and transcardially perfused with ice-cold sterile $0.9 \%$ sodium chloride (saline). The spinal cord was quickly removed and placed in a small Petri dish filled with fresh ice-cold saline. To identify differences in the protein profile of the CST temporally (i.e., to see what proteins are highly expressed in the developing vs more mature CST), tissue was collected from the CST in the cervical spinal cord of rats at P 0, 3, 14 and 28 (Fig. 1A). To identify differences between the protein profile of the developing CST and other developing tracts of the spinal cord, tissue was separately collected from the CST and two other white matter tracts of the spinal cord from P3aged animals (a period of heightened corticospinal development) (Fig. 1B).

For a temporal analysis, dissected tissue from each animal (8 animals per time point) was homogenised individually in 4 volumes (w/v) of $6 \mathrm{M}$ urea, 2M thiourea, 2\% 3-((3cholamidopropyl)dimethylammonio)-1-propanesulfonic acid (CHAPS) and $0.5 \%$ sodium dodecyl sulphate (SDS) using a pellet pestle (30 strokes with the pestle, left on ice for 10 minutes, followed by another 30 strokes with the pestle). The extracts were sonicated briefly and left on ice for 10 minutes, followed by centrifugation at $13,000 \mathrm{~g}$ for 10 minutes at $4{ }^{\circ} \mathrm{C}$ to pellet any insoluble material. For mass spectrometry analysis, aliquots of extracted proteins from each sample group were pooled and precipitated in 6 volumes of ice-cold acetone overnight at $-20^{\circ} \mathrm{C}$. The remaining extracts were stored un-pooled at $-80^{\circ} \mathrm{C}$ for western blotting. The acetone

precipitates were pelleted by centrifugation at $13,000 \mathrm{x}$ g for 10 minutes at $4{ }^{\circ} \mathrm{C}$ and the supernatant was carefully removed and discarded. The pellets were resuspended in $500 \mathrm{mM}$ 
triethylammonium bicarbonate (TEAB). The protein concentration in each sample was determined using a Bradford protein assay.

For a spatial analysis, tissues dissected from the corticospinal, lateral, and ventral white matter tracts at P3 were relatively small. To minimise sample loss during extraction, tissue from each region ( 8 animals per region) was pooled prior to extraction. The pooled tissue was then extracted, prepared and stored, as described above for the temporal analysis.

\subsection{Sample preparation for mass spectrometry analysis}

Reduction, alkylation, and digestion steps were performed using the reagents and recommendations detailed in the isobaric tags for relative and absolute quantitation (iTRAQ) labelling kit. The extracts were digested with trypsin overnight at $37^{\circ} \mathrm{C}$, followed by iTRAQ labelling by incubating each tag with $85 \mu \mathrm{g}$ of total protein from one of the samples (as per manufacturer's instructions; ABSciex, Foster City, CA, USA).

\subsection{Cation exchange fractionation}

The combined 4-plex iTRAQ labelled peptides were concentrated (vacuum concentrator, ThermoSavant, ThermoFisher Scientific, Waltham, MA, USA) and resuspended in $0.6 \mathrm{~mL}$ load buffer Ascx (10 mM KH $2 \mathrm{PO}_{4}, 20 \%$ acetonitrile $\left.(\mathrm{MeCN}), \mathrm{pH} 3.0\right)$ and sonicated. The pH was measured and adjusted, where necessary, to 3.0 with $0.5 \mathrm{M} \mathrm{H}_{3} \mathrm{PO}_{4}$. The peptides were then separated by strong cation exchange chromatography on a PolySulfoethyl A column (200 mm x $2.1 \mathrm{~mm}, 5 \mu \mathrm{m}, 200 \mathrm{~nm}$ pore size, PolyLC, Columbia, MD, USA). The column was washed with

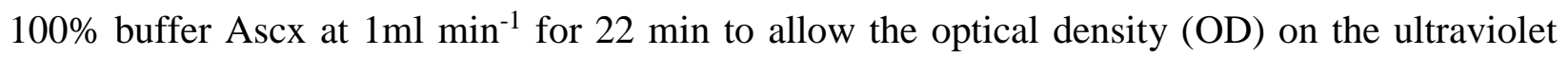

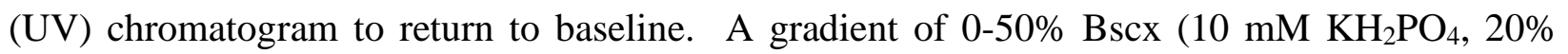
MeCN, $500 \mathrm{mM} \mathrm{KCl}$, pH 3.0) was applied for $20 \mathrm{~min}, 50-100 \%$ Bscx for $3 \mathrm{~min}$, followed by $100 \%$ Bscx for a further 3 min to wash the column, before re-equilibration in $100 \%$ Ascx for

another $11 \mathrm{~min}$. Fractions $(0.5 \mathrm{~mL})$ were collected every $30 \mathrm{sec}$. The UV chromatogram was inspected and fractions pooled to give 7 fractions (temporal comparison) and 11 fractions (spatial 
comparison) of similar peptide concentration across the elution profile. The pooled fractions were then concentrated in a vacuum concentrator and resuspended in $0.1 \%$ FA. They were then desalted on C18 spin columns (PepClean C18 spin columns, ThermoFisher Scientific, Waltham, MA, USA) using the manufacturer's instructions, eluting in $20 \mu 170 \% \mathrm{MeCN}$. The elution solvent was removed by vacuum concentration and the fractions resuspended in $20 \mu 10.1 \%$ formic acid (FA) prior to mass spectrometric analysis.

\subsection{Mass spectrometry analysis}

Each fraction $(10 \mu \mathrm{l})$ was then analysed by nanoflowLC-ESI-MSMS. The peptides were separated using a nanoLC Ultra 2D plus loading pump and nanoLC AS-2 autosampler chromatography system (Eksigent, Redwood City, CA, USA), using a PepMap RSLC column $(75 \mu \mathrm{m} \times 15 \mathrm{~cm})$ and an Acclaim PepMap100 trap $(100 \mu \mathrm{m} \times 2 \mathrm{~cm})$ (ThermoFisher Scientific, Waltham, MA, USA). After washing the peptides on the trap column for $20 \mathrm{~min}$ at $5 \mu \mathrm{L} \mathrm{min}^{-1}$, the trap was switched in line with the column and the peptides eluted with a gradient of increasing $\mathrm{MeCN}$ from $95 \%$ buffer A $(98 \% \mathrm{H} 2 \mathrm{O}, 2 \% \mathrm{MeCN}, 0.1 \% \mathrm{FA}), 5 \%$ buffer B (2\% H2O, $98 \% \mathrm{MeCN}, 0.1 \% \mathrm{FA}$ ) to $65 \%$ buffer A, $35 \%$ buffer B over 60 min, then to $50 \%$ buffer A, $50 \%$ buffer B over a further $20 \mathrm{~min}$, before increasing the concentration of buffer B to $95 \%$ over a further 10 min. The column was then washed with $95 \%$ buffer B before re-equilibration in $95 \%$ buffer A. A flow rate of $300 \mathrm{~nL} \mathrm{~min}^{-1}$ was employed. The eluent was sprayed into a TripleTOF 5600 tandem mass spectrometer (ABSciex, Foster City, CA, USA ), using a NANOSpray III source, and analysed in Information Dependent Acquisition (IDA) mode, performing $250 \mathrm{~ms}$ of MS followed by 100 ms MSMS analyses on the 20 most intense peaks with a charge state of +2 to +5 . Parent (MS) ions were accepted with a mass tolerance of $50 \mathrm{mDa}$ and MSMS was conducted with a rolling collision energy (CE) inclusive of preset iTRAQ CE adjustments. Analysed parent ions were then excluded from analysis for 13 seconds after 3 occurrences. The raw data file generated was subsequently analysed using ProteinPilot 4.5 software with the Paragon $^{\mathrm{TM}}$ and ProGroup ${ }^{\mathrm{TM}}$ algorithms (ABSciex) against the Swiss-Prot database (accessed 1st July 2013 and 1st Dec 2013 for the temporal and spatial experiments, respectively). Searches were performed using the preset iTRAQ settings in ProteinPilot with trypsin as the cleavage 
enzyme and MMTS modification of cysteines, 'Bias' and 'Background' corrections selected, and with a 'Thorough ID' search effort. The database search was restricted to a rat only search (containing 15686 proteins on the July 2013 search and 15662 on the Dec 2013 search). Finally, detected proteins were reported with a Protein Threshold (Unused ProtScore (conf)) > 0.05, using those peptides autoselected by ProteinPilot. In each case the accession number for the protein designated the 'representative winner protein' by the ProGroup algorithm is given. Accession numbers for all proteins that were combined into a group are available in the ProteinPilot raw data files, and these will be made available, via ftp access, upon request. A False Discovery Rate (FDR) analysis was also performed using ProteinPilot software.

\subsection{SDS-polyacrylamide gel electrophoresis and western blotting}

Protein extracts were prepared by boiling in SDS loading buffer (2\% SDS, 5\% 2mercaptoethanol, $62.5 \mathrm{mM}$ Tris-HCl, $\mathrm{pH} \mathrm{6.8),} \mathrm{for} 2 \mathrm{~min}$. Proteins were subjected to SDS-PAGE using $15 \%$ polyacrylamide gels and transferred to nitrocellulose membranes by western blotting. After blocking non-specific sites with $4 \%$ powdered milk solution, membranes were incubated with a rabbit anti-stathmin primary antibody (Proteintech Europe, Manchester, UK, catNo:11157-1-ap): diluted to 1:1000 in phosphate buffered saline (PBS) containing 1\% fetal bovine serum, $1 \%$ horse serum and $0.1 \%$ bovine serume albumin (BSA). Antibody reacting bands were visualised by development with peroxidase-labeled swine anti-rabbit $\operatorname{IgG}(1 \mu \mathrm{g} / \mathrm{mL}$ in dilution buffer) and a chemiluminescent detection system (West Pico, Pierce Biotechnology, Rockford, IL, USA). In control experiments the secondary swine anti-rabbit IgG antibody did not show any reactivity against corticospinal tract extracts (data not shown).

\subsection{Stathmin immunohistochemistry in the developing rat spinal cord}

To characterise the expression of stathmin in the spinal cord throughout the period of CST development, rats at P0, P3, P5, P7, P10, and P14 stages of development were given an overdose of pentobarbitone anaesthetic (via i.p. injection) and transcardially perfused with ice- 
cold 4\% PFA. The cervical spinal cord was quickly removed and placed in fresh ice-cold PFA overnight. Specimens were subsequently transferred to a $30 \%$ sucrose solution in tris-buffered saline (TBS), and allowed to fully sink in the solution at RT. The specimens were placed on a sliding, freezing microtome, and $40 \mu \mathrm{m}$ cross sections cut through full length of the cervical enlargement of the spinal cord. Sections were stored in 24-well plates containing TBS with sodium azide.

For immunohistochemistry, sections were first subjected to antigen retrieval by incubation in sodium citrate buffer $(10 \mathrm{mM}$ sodium citrate, $0.05 \%$ Tween $20, \mathrm{pH} 6.0)$ at $95^{\circ} \mathrm{C}$ for 30 minutes. Sections were then rinsed 3 times in TBS, and incubated in a blocking solution containing 3\% goat serum / TBS for 1 hour at RT. The blocking solution was subsequently replaced with a rabbit anti-stathmin primary antibody, diluted to 1:100 (Proteintech Europe, Manchester, UK, catNo:11157-1-ap) in TBS containing 1\% goat serum, and left to incubate overnight at RT. The following day, sections were rinsed 3 times in TBS followed by a 2 hour incubation in a 1:200 dilution of anti-rabbit 596 fluorescent secondary antibody (Molecular Probes, Eugene, OR, USA). Subsequently, sections were rinsed 3 times in TBS, mounted onto slides, and coverslipped using Vectashield Hardmount mounting media (Vector Laboratories Inc., Burlingame, CA, USA). Fluorescent images were acquired using a Hamamatsu digital CCD camera attached to a Nikon Eclipse 80i microscope (Nikon Corporation, Tokyo, Japan). Confocal images were acquired using a Leica SP5 confocal microscope with a 63x oil immersion objective.

\subsection{Stathmin immunohistochemistry in the human fetal brain}

The postmortem brain specimens used here are part of the large and versatile Zagreb Collection (Judaš et al., 2011; Krušlin et al., 2014). Brain specimens were obtained either from medically indicated or spontaneous abortions, or subsequent to the death of prematurely born infants at several clinical and pathological departments of the University of Zagreb, School of Medicine. The procedure for the human autopsy and collection of postmortem brain samples has been approved by the Institutional Review Board and the parental consent for postmortem examination was obtained in all cases. The fetal age was estimated on the basis of crown-rump 
length (CRL, in $\mathrm{mm}$ ) and pregnancy records, and expressed as weeks of gestation (wg). In addition, the correlation of maturational parameters (CRL, body mass, pregnancy records, and sonographic examination) revealed no evidence of growth retardation or malformations. Specimens in which subsequent postmortem analysis revealed macroscopical or microscopical pathological changes were excluded from the study.

The entire brains were fixed by immersion in $4 \%$ paraformaldehyde (PFA) in $0.1 \mathrm{M}$ PBS (pH 7.4). Subsequently, tissue blocks were embedded in paraffin wax (Histowax, Jung, Nussloch, Germany) and serially cut in $15 \mu \mathrm{m}$ thick sections. After deparaffinization in xylene, the section were collected in $70 \%$ ethanol, put in $50 \%$ and then in $5 \%$ ethanol, then put in distilled water, and finally in a staining solution which consisted of 1 part $0.5 \%$ cresyl-violet in distilled water mixed with 4 parts of distilled water (Nissl stain). Upon achieving adequate staining, the section were placed in distilled water, then passed through a graded alcohol series and finally in ether-ethanol solution ( 2 parts of ether and 1 part of $100 \%$ ethanol), rinsed with xylene, and mounted. While Nissl staining was used to delineate cytoarchitectonic boundaries and cellular compartments, adjacent histological sections were processed with an indirect immunohistochemical method using a rabbit anti-stathmin polyclonal (Proteintech Europe, Manchester, UK, catNo:11157-1-ap) in final dilution 1:1600 and biotinylated secondary antirabbit antibody from Vectastain ABC kit (Vector Laboratories Inc., Burlingame, CA, USA). After dewaxing in alcohol, rehydration in PBS and microwave-retrieval, the sections were pretreated for 20 minutes in $0.3 \%$ hydrogen peroxide in the $3: 1$ mixture of methanol and redistilled water, washed for 10 minutes in the PBS, and immersed for 2 hours in the blocking solution (PBS containing 3\% BSA and 0.5\% Triton X-100, both from Sigma, St. Louis, MO, USA) at RT to prevent non-specific background staining. Sections were then incubated with anti-stathmin for 18 hours at $4^{\circ} \mathrm{C}$, washed again, and further incubated with secondary anti-rabbit antibodies diluted in blocking solution (1:200) for 1 hour at RT (Vectastain ABC kit, Vector Laboratories, Burlingame, CA, USA). Subsequently, sections were incubated in Vectastain ABC reagent (streptavidin-peroxidase complex) for 1 hour at RT, rinsed in PBS for 10 minutes, while the peroxidase activity was visualized with Ni-DAB (nickel-enhanced 3,3-diaminobenzidine kit; Sigma, St. Louis, MO, USA). Sections were dehydrated in a graded series of alcohol, cleared in xylene and cover-slipped with Histomount (National Diagnostic, Atlanta, GA, USA). Negative controls were included in all immunohistochemical experiments either by replacing it with an 
inappropriate secondary antibody or by omitting the secondary antibody. No immunolabeling was detected in control sections (data not shown).

For the analysis of STATHMIN expression we used previously published microarray database (Kang et al., 2011) available from the Gene Expression Omnibus (GEO accession GSE 25219, Human Exon 1.0 ST Array). The dataset is composed of 1340 brain tissue samples encompassing the entire human lifespan (age range 5 PCW - 82 years) and covering 16 brain regions (for details see Kang et al., 2011). Partek Genomic Suite 6.6 (Partek Inc., St. Louis, MO, USA) was used to normalize data and summarize probe set and transcript clusters. Affymetrix CEL files were imported into Partek Genomic Suite using default Partek settings. Analysis was done on the probe sets designated as 'core' and 'extended' using Partek Genomic Suite 6.6 and R Statistical Software Package (http://www.r-project.org). The median of all probesets within one gene was used as the estimate of gene expression. A gene was considered to be expressed if the $\log 2$-transformed expression value in the analyzed sample was $\geq 5.5$.

\subsection{Primary cortical neuron culture and drug-treatment}

Embryonic day 17 (E17) time-mated rats (day of plugging = E0) were given an overdose of pentobarbitone anaesthetic via i.p. injection. Whole E17 brains were dissection in ice cold Hanks Balanced Salt Solution (HBSS), and the approximate area of the emerging motor cortex (Miller, 1987; Schreyer and Jones, 1988) dissected free and the meninges were carefully removed. The cortical tissue was placed in ice cold Dulbeco's Modified Eagle's medium (DMEM)-based culture media containing $10 \%$ fetal calf serum, $1 \%$ B27, and 1\% penicillinstreptomyacin with fungizone, and mechanically dissociated. Cells were resuspended in fresh media to a concentration of 3.7 million cells / $\mathrm{mL}$, and drop cultures formed by placing a $10 \mu \mathrm{L}$ sample of the cell suspension ( $\sim 37,000$ cells) onto glass coverslips coated with poly-D-lysine in a 24 well culture plate. Cells were left to settle for 10 minutes, and then the culture wells were filled with $0.5 \mathrm{~mL}$ of culture media containing either $1,4,16$, or $32 \mu \mathrm{M}$ of the p38 / p38 $\beta$ MAP kinase inhibitor, SB203580 (InvivoGen), dissolved in dimethyl sulfoxide (DMSO), or culture media with DMSO added as a vehicle control. This particular inhibitor was chosen because it has been shown to affect the microtubule destabilization activity of stathmin in PC12 cells by 
attenuating its phosphorylation (Mizumura et al., 2006). Three coverslips were prepared for each culture condition, and the cells grown in an incubator set at $37^{\circ} \mathrm{C}, 5 \% \mathrm{CO}_{2}$ and $95 \%$ humidity for 72 hours. Subsequently, the culture media was aspirated off and the cells fixed in an acetone: methanol (1:1) solution. After 10 minutes this solution was aspirated off and the wells allowed to dry for a further 10 minutes. The cells were then rinsed 3 times in TBS, and incubated in a 1:1000 dilution of mouse anti- $\beta$ III tubulin (Covance; to visualize the morphology of neurons), and 1:200 dilution of rabbit anti-stathmin 1 (Proteintech) in TBS for 2 hours. The coverslips were then rinsed 3 times in TBS, followed by a 1 hour incubation in a 1:200 dilution of goat antimouse 488, and goat anti-rabbit 594 secondary antibodies. Cell nuclei were counterstained with 4',6-diamidino-2-phenylindole (DAPI) for 15 minutes just before finally rinsing the cells 3 times in TBS and mounting onto slides with hydromount media (National Diagnostics).

To quantify outgrowth of neuronal processes, an image was taken through a 10x magnification lens of the centre of each drop culture. All freely growing $\beta$ III tubulin processes in the field of view were measured from the cell soma outward using the Nikon NIS elements software program (Nikon). Measures of neurite length were exported to Microsoft Excel, and one-way analysis of variance (ANOVA) performed (to assess for any differences within the groups) followed by a Tukey's post hoc analysis (to identify significant differences).

\section{Results}

3.1 Proteins associated with cellular assembly and organisation are enriched during development of the rat CST

To identify temporal expression patterns, tissue was collected from the CST (i.e., the ventral most portion of the dorsal funiculus; Fig. 1A) of rats at P 0, 3, 14 and 28 . These represented early (P0) and mid (P3) developmental stages, as well as fully-developed stages (i.e., P14 and P28) where the tract has fully extended the length of the spinal cord. The adult (P28) tissue contained particularly high levels of insoluble material (most likely to be myelin), making total protein extraction unreliable for quantitative mass spectrometry analysis from this group. 
However, the use of tissue from P14 - when the CST has projected the length of the rat spinal cord (Nagashima, 1994) - allowed for a comparison against proteins expressed during axonal growth of the CST from P0 through P3 with those found in the fully extended CST. The precision of the dissection was examined by western blotting with an antibody against the nuclear pore protein, nucleoporin 160 (NUP160). NUP160 was undetectable in the CST extracts at P0 and P3; thus suggesting that contamination of the CST extract with cellular material from surrounding grey matter was negligible at these time points (Supplementary file, Fig. 1). The faint detection of NUP160 at P14 and stronger detection at P21 correlates well with the known increase in myelination at this time and suggests that oligodendrocytes were present in material that was dissected from the fully-grown CST, as expected.

To identify and compare relative expression levels of proteins found in these tissues, we conducted a 3-plex iTRAQ mass spectrometry experiment (see methods). This approach detected 1,545 proteins, with a 5\% local FDR threshold. The full protein and peptide summaries are presented as separate tabs in Supplementary Table 1. After discarding any proteins that were identified with less than three peptides, a 1.25 fold change cut-off filter was applied to the remaining proteins. Using these criteria, the iTRAQ analysis identified the increased expression of 65 proteins in early (P0) and 36 proteins in mid stages (P3) of CST formation, in comparison to the fully-grown CST (P14) (Supplementary Table 2). It was assumed that a number of proteins with increased expression at P14, compared to P0 and P3, may to be related to the presence of oligodendrocytes and so we chose to focus analysis only on those that were increased in expression at P0 and P3 (compared to P14).

In order to gain some understanding of the molecular and cellular functions that the proteins with increased expression in the CST at P0 and P3 are involved in, bioinformatics analysis was undertaken using Ingenuity Pathway Analysis software (IPA; Qiagen, Redwood City, CA, USA, www.qiagen.com/ingenuity). Functional annotations that were assigned a pvalue $>0.05$ were removed from the list. The highest-ranking category that was associated with the up-regulated proteins at both P0 and P3 was "cellular assembly and organisation", and the highest ranking annotations within this category were related to cytoskeletal organisation, microtubule dynamics and neurite outgrowth, in both cases (Table 1). Canonical pathway analysis revealed that semaphorin signalling in neurons was the most enriched pathway at both P0 and P3, compared to P14 (Table 2). This finding supports previous observations that 
semaphorin signalling is important for growth and pathfinding of corticospinal fibres as they exit the cortex (Bagnard et al., 1998). 


\begin{tabular}{|c|c|c|}
\hline \multicolumn{3}{|l|}{ Up at P0 vs P14 } \\
\hline Name & p-value & Number of proteins \\
\hline $\begin{array}{l}\text { Cellular Assembly and Organization } \\
\text { Top } 5 \text { annotations in this category: } \\
\text { neuritogenesis } \\
\text { microtubule dynamics } \\
\text { quantity of microtubules } \\
\text { organization of cytoskeleton } \\
\text { formation of cellular protrusions }\end{array}$ & 8.23E-09 - 3.01E-02 & 32 \\
\hline Cellular Function and Maintenance & 8.23E-09 - 3.01E-02 & 29 \\
\hline RNA Post-Transcription Modification & 1.90E-08 - 1.14E-02 & 11 \\
\hline Cell Death and Survival & $3.09 \mathrm{E}-08-2.93 \mathrm{E}-02$ & 38 \\
\hline Molecular Transport & $1.16 \mathrm{E}-07-3.01 \mathrm{E}-02$ & 21 \\
\hline \multicolumn{3}{|l|}{ Up at P3 vs P14 } \\
\hline Name & p-value & Number of proteins \\
\hline $\begin{array}{l}\text { Cellular Assembly and Organization } \\
\text { Top } 5 \text { annotions in this category: } \\
\text { Growth of neurites } \\
\text { Outgrowth of neurite } \\
\text { microtubule dynamics } \\
\text { organization of cytoskeleton } \\
\text { formation of cellular protrusions }\end{array}$ & $9.23 \mathrm{E}-09-3.16 \mathrm{E}-02$ & 25 \\
\hline Cell morphology & $2.36 \mathrm{E}-08-3.64 \mathrm{E}-02$ & 19 \\
\hline Cellular Function and Maintenance & 3.67E-07 - 3.40E-02 & 22 \\
\hline Cell Death and Survival & $8.54 \mathrm{E}-06-3.40 \mathrm{E}-02$ & 27 \\
\hline Cell Development & 2.04E-05 - 3.40E-02 & 19 \\
\hline
\end{tabular}

Table 1: Molecular and cellular functions of proteins that were increased in expression during development of the CST. Ingenuity Pathway Analysis software (IPA) was used to assign molecular and cellular functional annotations to the proteins that were increased in expression at $\mathrm{P} 0$ and $\mathrm{P} 3$ compared to P14. The top five, significant (i.e. pvalue $<0.05$ ), annotations are shown for each comparison. 


\begin{tabular}{|c|c|c|}
\hline \multicolumn{3}{|l|}{ Up at P0 vs P14 } \\
\hline Name & p-value & Ratio \\
\hline Semaphorin Signalling in Neurons & $1.58 \mathrm{E}-06$ & $5 / 54(0.093)$ \\
\hline EIF2 Signalling & 7.65E-05 & $6 / 201(0.03)$ \\
\hline 14-3-3-mediated Signalling & $1.11 \mathrm{E}-03$ & $4 / 121(0.033)$ \\
\hline Protein Ubiquitination Pathway & 3.09E-03 & $5 / 270(0.019)$ \\
\hline Germ Cell-Sertoli Cell Junction Signalling & 3.19E-03 & $4 / 169(0.024)$ \\
\hline \multicolumn{3}{|l|}{ Up at P3 vs P14 } \\
\hline Name & p-value & Ratio \\
\hline Semaphorin Signalling in Neurons & 8.08E-06 & $4 / 54(0.074)$ \\
\hline Axonal Guidance Signalling & $4.24 \mathrm{E}-03$ & $5 / 483(0.01)$ \\
\hline Acute Phase Response Signalling & 8.64E-03 & $3 / 181(0.017)$ \\
\hline Angiopoietin Signalling & 1.19E-02 & $2 / 75(0.027)$ \\
\hline Ephrin B Signalling & $1.51 \mathrm{E}-02$ & 2/82 (0.024) \\
\hline
\end{tabular}

Table 2: Canonical pathways that were enriched in the up-regulated proteins during development of the CST: Ingenuity Pathway Analysis software (IPA) was used to determine the canonical pathways of proteins that were increased in expression at P0 and P3 compared to P14. The top five, significant (i.e. p-value $<0.05$ ), annotations are shown for each comparison. Ratio refers to the number of differentially expressed proteins that map to each pathway divided by the total number of proteins in the particular pathway. 
3.2 Stathmin is highly enriched in the developing rat CST compared to other developing descending and ascending spinal tracts

To identify protein expression that is enriched in the developing CST compared to other developing descending and ascending spinal tracts, tissue from the lateral and ventral white matter regions of the spinal cord were extracted from age matched animals (all at P3) for

A

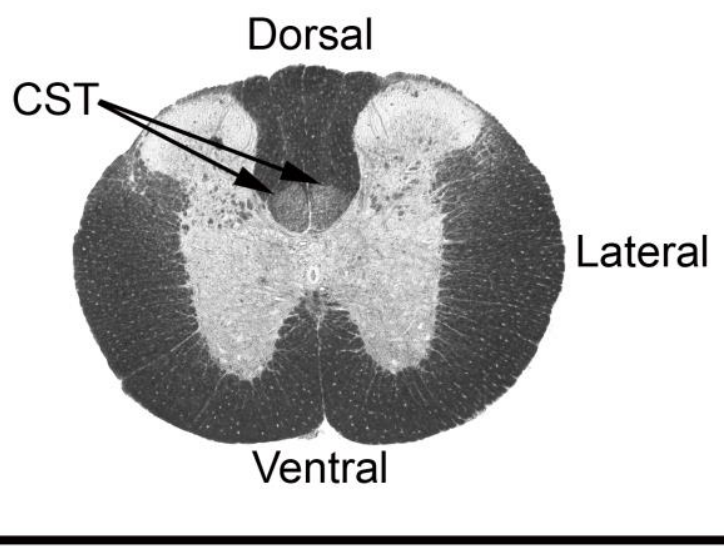

B

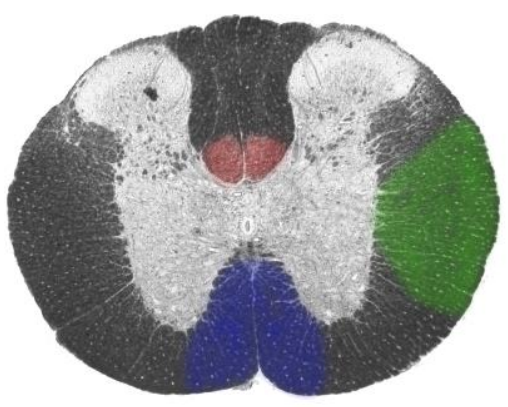

comparison with tissue extracted from the CST itself (Fig. 1). This spatial study took advantage of the ongoing development of the upper (i.e., cervical - thoracic) portion of the CST at postnatal day 3 to identify proteins that are specifically associated with development of the CST and no other spinal cord tracts. The presence of a nuclear pore protein, NUP160, was undetectable in these extracts by western blotting; suggesting that contamination of these extracts with cellular material from the surrounding grey matter and/or oligodendrocytes was negligible (Supplementary Fig. 1). This approach, under the same conditions used for the temporal study, detected 2,585 proteins, with a $5 \%$ local FDR threshold. The full protein and peptide

Figure 1: Diagram illustrating regions of the spinal cord used to identify temporally and spatially specific protein expression in the developing spinal cord. (A) An unstained, bright field image of a cross section through the adult rat spinal cord illustrating the position (arrows) of the corticospinal tract (CST) in rats. (B) To detail protein expression in the CST as it develops, protein was extracted from the CST (red shaded area) at P0, P3, P14 and adult rats and analysed using iTRAQ. Note that, unlike the human corticospinal projection, the CST fibers in rats predominantly traverse the ventral segment of the dorsal column of the spinal cord. To compare spatial difference in protein expression in developing white matter tracts of the spinal cord, protein was extracted from the CST (red shaded area) of P3 rats, and compared to the proteins expressed in the lateral (green shaded area) and ventral (blue shaded area) white matter tracts of the same animals. 
summaries are given as separate tabs in Supplementary Table 1.

As with the temporal analysis, a cut off was applied to proteins that were detected in the three regions of the developing P3 spinal cord; i.e., those that were identified using less than three peptides, or having less than a 1.25 fold change were excluded from further analyses. Using these criteria, the iTRAQ analysis identified 22 proteins that were more highly expressed within the CST, compared to the other developing white matter tracts of the spinal cord that were analysed (Supplementary Table 2). Bioinformatics analysis of these proteins, using IPA software, revealed that "cellular assembly and organization" was again the highest-ranking association of this dataset to biological functions. The highest-ranking annotations within this

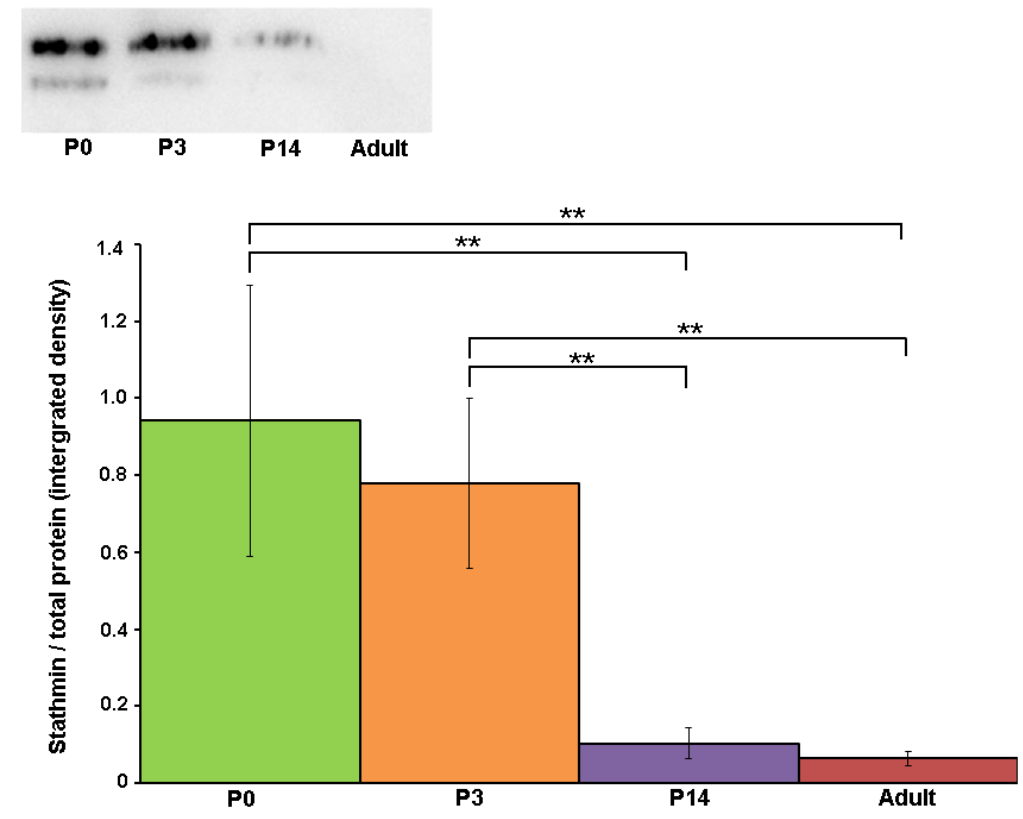
category were related to the formation, polymerisation and quantity of microtubules.

Of the 22 proteins that were enriched in the CST compared to other white matter tracts, only one, stathmin 1 - a protein known to be involved in microtubule dynamics - also had a highly enriched pattern of expression during CST development in the temporal analysis. A multiple sequence

\section{Figure 2: Western blot analysis verifies the differential expression of stathmin during} development of the rat corticospinal tract. Protein extracts were subjected to SDS-PAGE, transferred to nitrocellulose by electroblotting and probed with antibody against stathmin. After visualization using a chemiluminescent system, the integrated density of the bands was measured using ImageJ software (public domain program, National Institutes of Health, Bethesda, MD, USA, rsb.info.nih.gov/ij/). In order to overcome possible variability in density due to sample loading, stathmin/total protein ratios were calculated by integrated density measurement of the stathmin-immunoreactive bands on the blot and a horizontal slice of the gel (prior to western blotting), that was stained with Coomassie Blue (i.e. P0 $=0.94$ (S.D. $0.35, \mathrm{P} 3=0.78$ (S.D. 0.22), P14 = 0.10 (S.D. 0.04) and adult $=0.06$ (S.D. 0.02). Statistical significance of the differential expression was calculated using one-way analysis of variance (ANOVA) after logarithmic transformation of the data. ${ }^{*}=\mathrm{p}$-value 0.001 to $<0.01$. Error bars represent standard deviation (S.D.). 
alignment with rat stathmin isoforms 1,2,3 and 4a confirmed that the sequence of the detected peptides were unique to the stathmin 1 isoform (Supplementary file, Fig. 2). This differential temporal expression of stathmin in the CST at P0 and P3, compared to P14 and adult tissue, was verified by western blot analysis (Fig. 2).

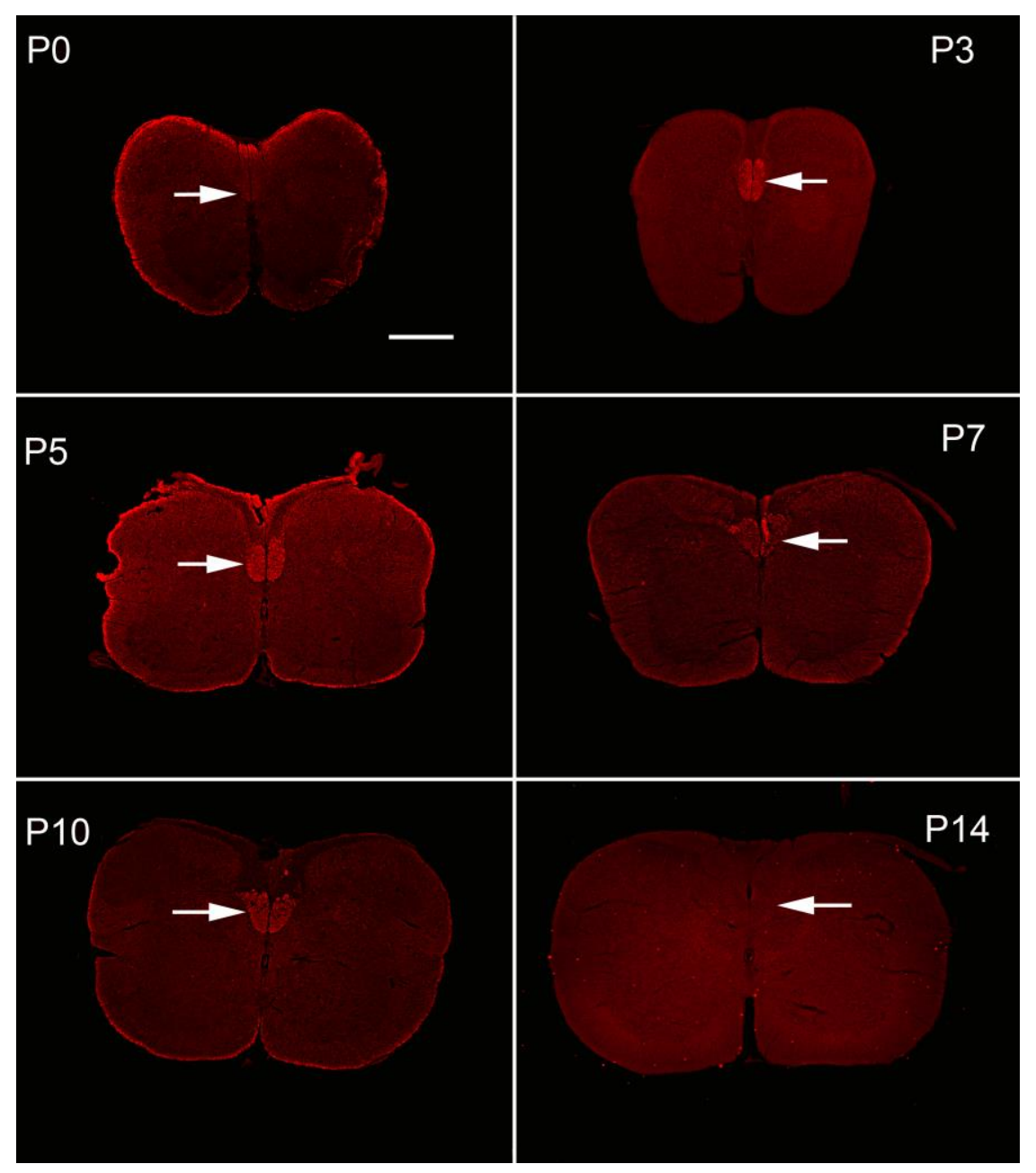

The spatial and temporal expression of stathmin in the developing spinal cord was further examined by immunohistochemical analysis of cross sections from the cervical region of the rat spinal cord throughout the first two weeks of development (Fig. 3). This revealed a high level of stathmin expression during ongoing development, from P3 to P10, which was almost exclusively restricted to the dorsal CST (Fig. 3). In

Figure 3: Immunohistochemical staining of the postnatal rat cervical spinal cord reveals high levels of stathmin expression in the corticospinal tract (CST) during the developmental period. At P0 stathmin staining initially appears in a very limited region (potentially representing the emerging CST) of the cervical cord, in the most ventral wedge of the dorsal columns (arrows). At P3 and P5 intense stathmin immunoreactivity appears restricted to the CST (arrows) with relatively low levels appearing in the surrounding grey matter or other white matter tracts . By P7 and P10 stathmin staining appears less intense in the CST than earlier developmental time points, though its expression was still only notable in the CST (arrows). By P14, stathmin staining was greatly reduced in the CST of the cervical cord, (arrow), and appeared to match that seen in all regions of the surrounding cord. Scale $=100 \mu \mathrm{m}$. 
agreement with iTRAQ and western blot analysis (Fig. 2), stathmin expression in the fully developed CST at P14 was no longer detectable (Fig. 3).

3.3 Stathmin expression is enriched along the corticospinal projection through the developing human brain

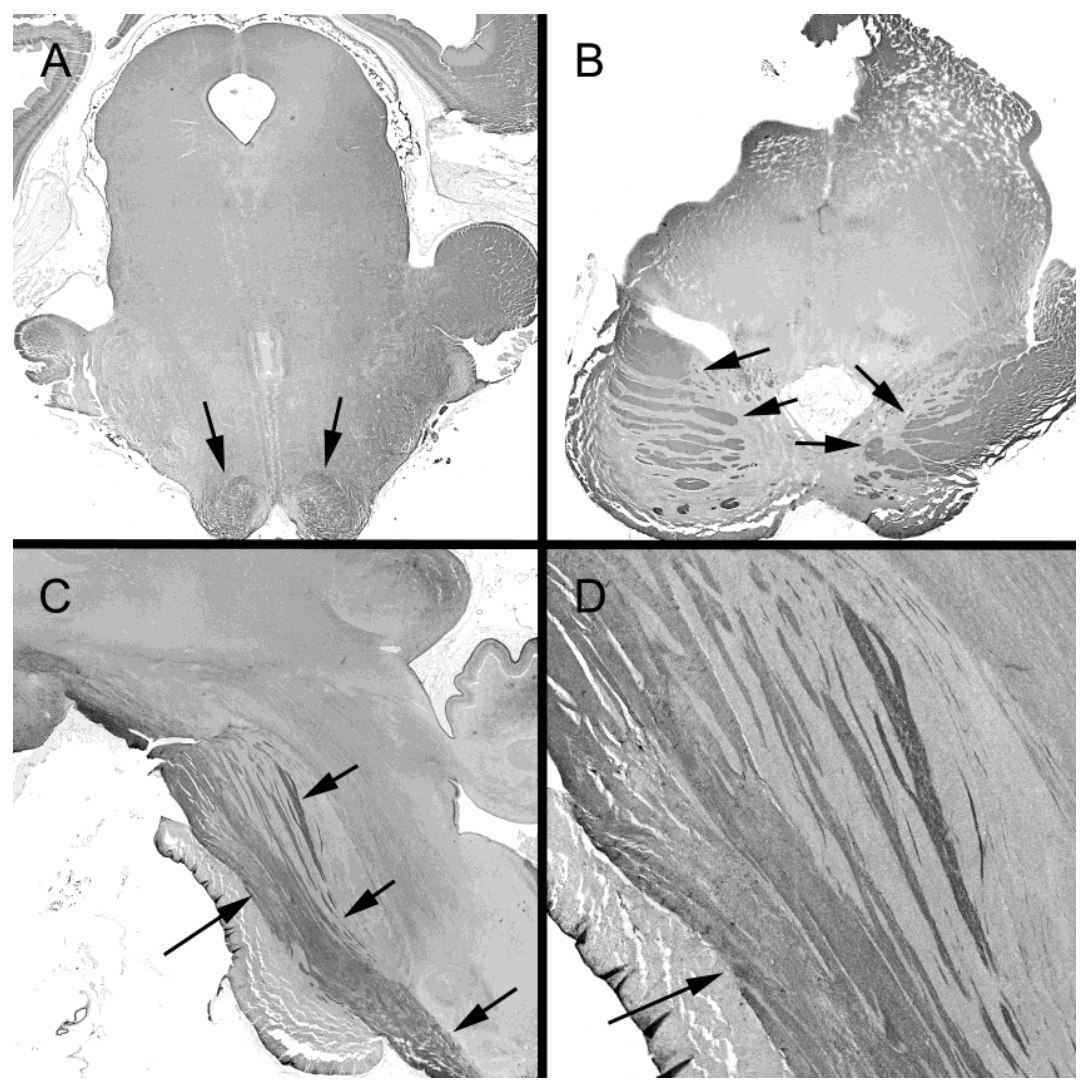

A restricted pattern of stathmin expression was also detected in transverse and sagittal sections of the fetal human brain stem (Fig. 4). Cross sections through the brain stem at $12 \mathrm{gw}$ revealed intense staining for stathmin in the CST at the level of the cerebral peduncles (Fig. 4A). At 16 and 18 gw (Figs. 4 B-D) relatively high levels of stathmin expression could be seen in the CST portion of the cerebral peduncles and

Figure 4: Immunohistochemical staining of the fetal human brain reveals high levels of stathmin expression in the developing corticospinal system of humans. (A) Cross section through the ventral portion of the human midbrain and brain stem, at $12^{\text {th }}$ gestational week (gw). Fine stathmin staining of the perpendicularly cut fibers passing through the medullary pyramidal tracts (arrows in A) are visible. (B) Similarly to A, a cross section through the fetal brain stem (at the level of pons and midbrain tegmentum) at $16^{\text {th }} \mathrm{gw}$ reveals fibrillary stathmin expression within the transpontine corticospinal (arrows) and other corticofugal fiber tracts. (C and D) Paramediosagittal section through the brain stem of the human telencephalon at $18^{\text {th }}$ gw showing clear, heavy fibrillary staining of stathmin in the cerebral peduncules as well as the transpontine cortico-fugal tract (arrows in $\mathrm{C}$ and D) down to the level of the medullary pyramids. 
transpontine-corticofugal system, in comparison to light or no staining in surrounding brain stem regions (e.g., the reticular formation and pons, respectively). Notwithstanding this restricted pattern of stathmin expression in the brain stem, the STMN1 gene is widely expressed in regions of the developing cerebellum, and diencephalon and telencephalon between $16 \mathrm{gw}$ and birth (Supplementary Fig 3).

\subsection{Reduction of neurite length following pharmacological perturbation of stathmin activity in} vitro

In order to determine the importance of stathmin activity for neurite outgrowth, immature neurons from an approximate area of the developing rat motor cortex at E17 were grown in the presence of several concentrations of the p38 $\alpha$ / p38 $\beta$ MAP kinase inhibitor, SB203580 (Han et al., 1994; Lee et al., 1994), alongside a vehicle control. While there was no significant difference in the length of neurite processes established by corticospinal neurons grown in vehicle control containing media compared to those grown in either $1 \mu \mathrm{M}$ or $4 \mu \mathrm{M}$ of SB203580, there were significantly sorter neurites established by neurons treated with either $16 \mu \mathrm{M}$ or $32 \mu \mathrm{M}$ (Fig. 5). Interestingly, while cells grown in vehicle control containing media grew long smooth neuritic process that had few large branching points (arrows in Fig. 5A), cells grown in high concentrations of SB203580 had thick extensions of the cell membranes, with neurites containing many fine poorly formed beta-tubulin III positive extensions (arrow heads Fig. 5A).

\section{Discussion}

Through the use of quantitative proteomics, western blot analysis, and immunohistochemical characterizations, we have demonstrated that the expression of stathmin 1 (a phosphoprotein known to coordinate the assembly / disassembly of microtubules) is enriched in the CST during development of both the postnatal rat spinal cord and fetal human brain stem. Additionally, this study has shown that perturbation of stathmin activity significantly affects process outgrowth 


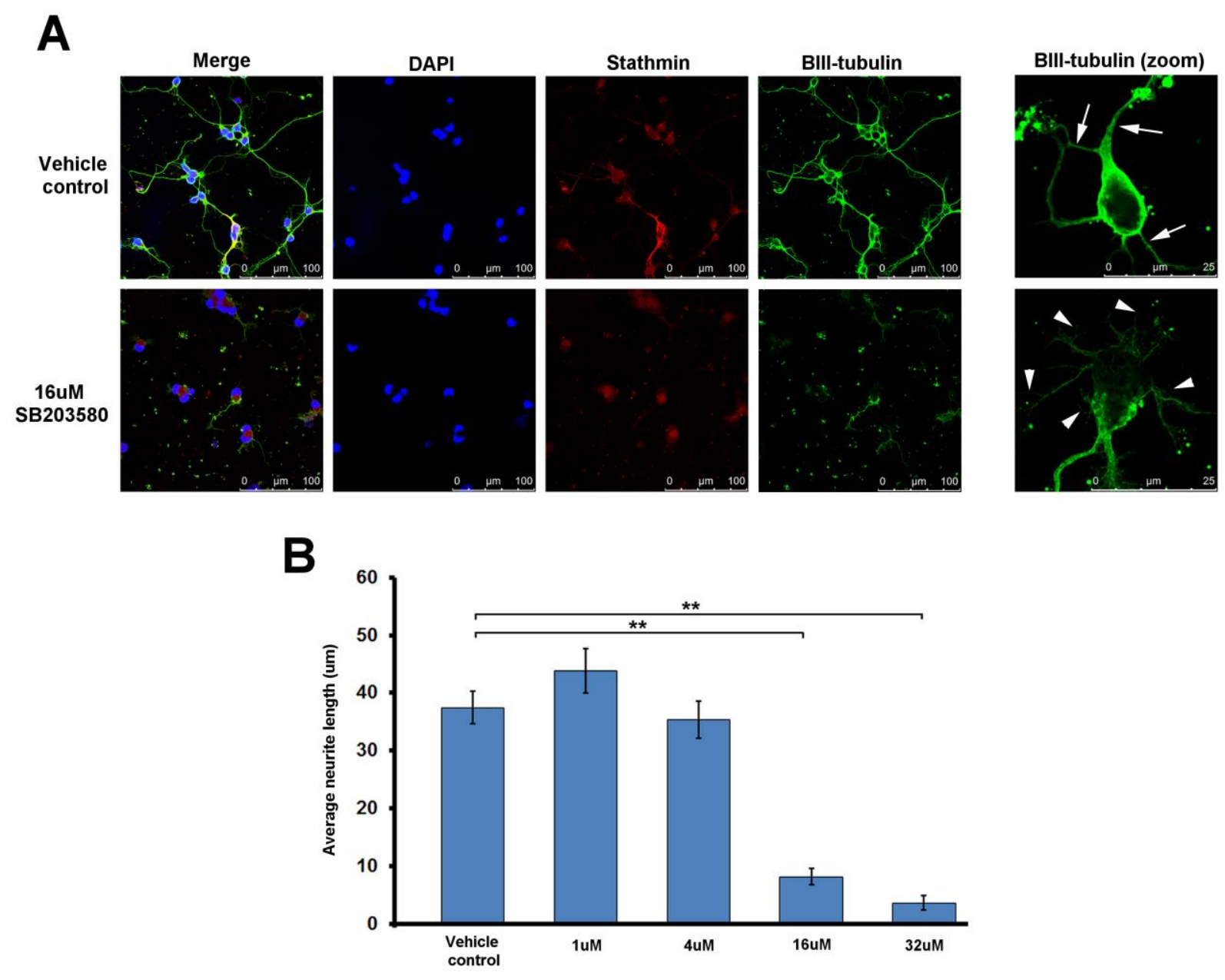

\section{Figure 5: Stathmin perturbation significantly affects neurite growth from embryonic} rat cortical neurons grown in vitro. (A) Immunohistochemical staining for beta III tubulin (green), stathmin (red) and DAPI (blue) of E17 rat cortical neurons grown in vehicle control containing media or $16 \mu \mathrm{M}$ of SB203580. While a number of long beta III tubulin+ processes were established by cells grown in vehicle control media, cells grown in the presence of high concentrations $(16 \mathrm{uM})$ of SB203580 showed short or no neurite growth. Stathmin immunoreactivity appeared relatively similar in both conditions, with obvious staining in the cell soma and finer staining in most neurites. Viewed at a higher magnification (shown on right), cells grown in control media appeared to establish long smooth neurite processes (arrows), while those established by cells grown in the presence of SB203580 appeared jagged, with many fine projections protruding off principle processes (arrowheads) (B) Counts of the average neurite length (in $\mu \mathrm{m}$ ) established by cells grown in control media, or in $1 \mu \mathrm{M}, 4 \mu \mathrm{M}, 16 \mu \mathrm{M}$ or $32 \mu \mathrm{M}$ of SB203580 (i.e. vehicle control $=37 \mu \mathrm{m}$ (S.E. 2.77 ), $1 \mu \mathrm{M}=$ $43.81 \mu \mathrm{m}$ (S.E. 3.83), $4 \mu \mathrm{M}=35.38 \mu \mathrm{m}$ (S.E. 3.15), $16 \mu \mathrm{M}=8.21 \mu \mathrm{m}$ (S.E. 1.47) and $32 \mu \mathrm{M}=$ $3.62 \mu \mathrm{m}$ (S.E. 1.23). ANOVA analysis revealed significant difference within the groups, and a post hoc Tukey's analysis indicated that cells treated with $16 \mu \mathrm{M}$ and $32 \mu \mathrm{M}$ SB203580 grew significantly shorter processes than cells in the control condition $(* * \mathrm{p}<0.01)$. There was no statistical difference in the neurite length of cells grown in control conditions in comparison to cells treated with either $1 \mu \mathrm{M}$ or $4 \mu \mathrm{M}$ of the drug. Error bars represent standard error (S.E.). 
from rat corticospinal neurons grown in culture. Taken together, these findings suggest that stathmin activity is an important modulator of axonal growth during development of the corticospinal projection.

Stathmin has long been associated with various forms and the invasiveness of cancer (Roos et al., 1993; Schubart et al., 1996; Marklund et al, 1996; Bacquero et al., 2012) as well as the response of neurons to growth-related proteins (Doye et al., 1990). While initial stathmin knockout studies in mice seemed to indicate that the protein had no notable effects on either neuronal development or tumor formation (Schubart et al., 1996), more detailed analysis indicated that stathmin deficient mice develop axonopathies in the spinal cord, primarily in motor tracts (Liedtke et al., 2002). In addition, a stathmin-knockout Drosophila model revealed major peripheral motor dysfunction, and deficiencies in maintaining long distance peripheral projections (Duncan et al., 2013). However, what effect stathmin activity might have on the development of the CST is yet not clear.

At present, it is known that stathmin coordinates the assembly and disassembly of microtubules in cells at various stages of maturation (Gavet et al., 2002), and that it may play a particularly crucial role in maintaining the microtubules of neurons during axonal growth (Duncan et al., 2013; Tortoriello et al., 2014). The importance of microtubule dynamics in the formation of the CST is highlighted in the bioinformatics analysis conducted here on proteins found to be enriched in expression during development of the rat spinal cord at P0 and P3. Ingenuity Pathway Analysis (IPA) of these proteins showed that "cellular assembly and organisation" is the most enriched function assigned to all proteins differentially expressed in the developing CST, and that the highest ranking annotations within this category is cytoskeletal organisation, microtubule dynamics, neurite outgrowth, and the formation, polymerisation and quantity of microtubules. However, some previous studies have also suggested that stathmin activity can negatively affect axonal growth. Studies of the protein DOCK 7 (which is involved in establishing the polarity of neurons, and is exclusive to the formation of the axonal process of developing neurons) showed that it negatively affects stathmin activity and (through this mechanism) enhances the elongation of axons (Watabe-Uchida et al., 2006). This work postulated that stathmin may be heavily involved in depolymerizing microtubules in axons, and that altering its activity may increase the sprouting of superfluous axonal branches. The latter concept is supported by work showing that mice rendered deficient in pituitary adenylate 
cyclase-activating polypeptide displayed high levels of stathmin production and an abnormal level of axonal projections in the dentate gyrus (Yamada et al., 2010). The potential for stathmin activity to have a negative effect on the growth of neurites is reinforced by our culture study. Cells treated with $16 \mathrm{uM}$ or $32 \mathrm{uM}$ of the p38 / p38 $\beta$ MAP kinase inhibitor SB203580 (which affects the phosphorylation status of stathmin, but not the expression of the protein itself), displayed a significant reduction in neurite growth in comparison to cells grown in media containing vehicle control or $1 \mathrm{uM}$ or $4 \mathrm{uM}$ of the drug.

However, the view that stathmin activity only negatively effects the growth of axonal projections may be overly simplistic, and begs the question of why stathmin expression is so enriched in a long distant axonal projection like the CST during development. Our immunohistochemical analysis of the developing spinal cord of the rat, shows that stathmin expression is particularly enriched in the CST during the principle period of its formation (i.e., P0-P10). Similarly, stathmin staining of the fetal human brain at 12, 16 and 18 gw shows that stathmin is highly expressed, relative to surrounding areas), in the CST region of the upper and lower brain stem during a period of development. This period corresponds to the time when CST neurons project through these structures just before reaching the spinal cord (Donkelaar et al., 2004).

One answer might be that a coordinated process of stabilisation and destabilisation, and not stabilisation alone, of microtubules may be essential for appropriate axonal development (Kurup et al., 2013). The potentially complex role of stathmin activity in axonal growth has been highlighted in Drosophila, which shows that the STAI gene (the STMN equivalent in flies) encodes a protein that sequesters dimers of microtubules very near polymerizing microtubules (Duncan et al., 2013). This position of the protein (between depolymerised and stabilized microtubules) suggests that it may be important for sequestering free microtubules for neurites to polymerise for growth ("axon rescue"), but may also be placed there to destabilize microtubules in aberrant or unwanted processes ("axon catastrophe"; Gardner et al., 2013; Chuckowree and Vickers, 2003) to recycle microtubules. In this respect, it is interesting to note that neurites established by cells treated with high concentrations of SB203580 appear to have superfluous branches along with shorter neurites (Fig. 5). An interesting possibility is that stathmin could perhaps be (both) destabilising microtubules too rapidly for long processes to be established while creating a greater pool of microtubules for neurites to form. Previous work showing that 
there is a relationship between increased expression of stathmin and schizophrenia, purportedly due to increased plasticity among neurons in the brain (Watabe-Uchida et al., 2006), would support such an explanation.

In the future, it will be important to fully understand the level of expression and function of stathmin in the adult central nervous system to determine its potential to play a positive or negative role during regenerative events, and if its manipulation may be an avenue to explore for increasing the regeneration of the CST after spinal cord injuries. Recent studies in both Drosophila and mice have shown that microtubule destabilisation may be an essential part of the regrowth of axons after injury (Stone et al., 2012; Cho and Cavalli, 2012). Though a great deal of effort has been placed on understanding the extracellular milieu surrounding injured spinal cord axons (e.g., Nogo, and L1; Cohen et al., 1998; Stein and Tessier-Lavigne, 2001; WienckenBarger et al., 2004), the intrinsic growth potential of injured CST axons should also be assessed to determine if the intra-cellular mechanisms necessary to bring about appropriate axonal growth responses are in place for regeneration to happen (Harel and Strittmatter, 2006). In this regard, the proteomic profiles identified in this study provide a useful resource for comparison against injury / regeneration models. If the expression of intra-cellular proteins (such as stathmin) is significantly altered (relatively to that seen during development) after a spinal cord injury, then it seems plausible that severed corticospinal axons may not be able to coordinate microtubule dynamics - making a positive growth response either unlikely or aberrant, regardless of the extracellular milieu.

\section{Acknowledgements}

This study was generously supported by a grant (20114975) from The Henry Smith Charity. We acknowledge the Wellcome Trust for funding the BSRC Mass Spectrometry and Proteomics Facility at the University of St Andrews and in particular for grant 094476/Z/10/Z to CHB which funded the mass spectrometer this work was carried out on and supported MAF. The work with human tissue by GSi, NJ-M, GSe and MB was supported by the Croatian Science Foundation Grant No. 09/16. The authors would like to thank Professor Glenn Morris (Wolfson Centre for Inherited Neuromuscular Disease, RJAH Orthopaedic Hospital) for providing some laboratory supplies and access to equipment. 


\section{Associated content}

Supplementary File 1, Supplementary Table 1 and Supplementary Table 2. 


\section{References}

Bagnard D, Lohrum M, Uziel D, Püschel AW and Bölz J (1998) Semaphorins act as attractive and repulsive guidance signals during the development of cortical projections. Dev 125:50435053

Baquero MT, Hanna JA, Neumeister V, Cheng H, Molinaro AM, Harris LN, Rimm DL (2012) Stathmin expression and its relationship to microtubule-associated protein tau and outcome in breast cancer. Cancer 118:4660-4669

Canty AJ and Murphy, M. (2008) Molecular mechanisms of axon guidance in the developing corticospinal tract. Prog Neurobiol 85:214-235

Cho Y and Cavalli, V. (2012) HDAC5 is a novel injury-regulated tubulin deacetylase controlling axon regeneration. EMBO J 31:3063-3078

Chuckowree JA and Vickers JC (2003) Cytoskeletal and morphological alterations underlying axonal sprouting after localized transaction of cortical neuron axons in vitro. $J$ Neurosci $23: 3715-3725$

Cohen NR, Taylor JS, Scott LB, Buillery RW, Soriano P and Furley AJ (1998) Errors in corticospinal axon guidance in mice lacking the neural cell adhesion molecule L1. Curr Biol $8: 26-33$

Dobson CB, Villagra F, Clowry GJ, Smith M, Kenwrick S, Donnai D, Miller S and Eyre JA (2001) Abnormal corticospinal function but normal axonal guidance in human L1CAM mutations. Brain 124:2393-2406

Donatelle JM (1977) Growth of the corticospinal tract and the development of placing reactions in the postnatal rat. J. Comp. Neurol. 175:207-231 
Donkelaar HJ, Lammens M, Wesseling P, Hori A, Keyser A and Rotteveel J (2004)

Development and malformations of the human pyramidal tract. J Neurol 251:1429-1442

Doye V, Boutterin MC, and Sobel, A (1990) Phosphorylation of stathmin and other proteins related to nerve growth factor-induced regulation of PC12 cells. J Biol Chem 265:11650-11655

Duncan JE, Lytle NK, Zuniga A, and Goldstein LS (2013) The microtubule regulatory protein stathmin is required to maintain the integrity of axonal microtubules in drosophila. PLoS One $8(6), \mathrm{e} 68324$

Finger JH, Bronson RT, Harris B, Johnson K, Przyborski SA and Ackerman SL (2002) The netrin 1 receptors Unc5h3 and Dcc are necessary at multiple choice points for the guidance of corticospinal tract axons. J Neurosci 22:10346-10356

Gardner MK, Zanic M, and Howard J (2013) Microtubule catastrophe and rescue. Curr. Opin. Cell Biol 25:14-22

Gavet O, El Messari S, Ozon S, and Sobel A (2002) Regulation and subcellular localization of the microtubule-destabilizing stathmin family phosphoproteins in cortical neurons. J Neurosci Res 68:535-550

Han J, Lee JD, Bibbs L and Ulevitch RJ (1994) A MAP kinase targeted by endotoxin and hyperosmolarity in mammalian cells. Science 265:808-811

Harel NY and Strittmatter SM (2006) Can regenerating axons recapitulate developmental guidance during recovery from spinal cord injury? Nat Rev Neurosci 7:603-616

Joosten EAJ and Gribnau AAM (1989) Astrocytes and guidance of outgrowing corticospinal tract axons in the rat. An immunocytochemical study using anti-vimentin and anti-glial fibrillary acidic protein. Neuroscience 31:439-452 
Judaš M, Šimić G, Petanjek Z, Jovanov-Milošević N, Pletikos M, Vasung L, Vukšić M and Kostović I (2011) The Zagreb Collection of human brains: a unique, versatile, but underexploited resource for the neuroscience community. Ann NY Acad Sci 1225 (Suppl. 1):E105-130

Kang HJ, Kawasawa YI, Cheng F, Zhu Y, Xu X, Li M, Sousa AM, Pletikos M, Meyer KA, Sedmak G, Guennel T, Shin Y, Johnson MB, Krsnik Z, Mayer S, Fertuzinhos S, Umlauf S, Lisgo SN, Vortmeyer A, Weinberger DR, Mane S, Hyde TM, Huttner A, Reimers M, Kleinman JE and Sestan N (2011) Spatio-temporal transcriptome of the human brain. Nature 478:483-489

Krušlin B, Džombeta T, Bezjak M, Sedmak G, Petanjek Z, Šimić G, Judaš M and Kostović I (2014) Congenital brain anomalies and chromosomal aberrations from the Zagreb Collection of human brains. Transl Neurosci 5:293-301

Kurup N, Sharifnia P, and Jin Y (2013) Spatial and temporal dynamics of neurite regrowth. Curr Opin Neurobiol 23:1011-1017

Lee JC, Laydon JT, McDonnell PC, Gallagher TF, Kumar S, Green D, McNulty D, Blumenthal MJ, Heys JR, Landvatter SW, Strickler JE, McLaughlin MM, Siemens IR, Fisher SM, Livi GP, White JR, Adams JL and Young PR (1994) A protein kinase involved in the regulation of inflammatory cytokine biosynthesis. Nature 372:739-746

Lee BB, Cripps RA, Fitzharris M and Wing PC (2014) The global map for traumatic spinal cord injury epidemiology: update 2011, global incidence rate. Spinal Cord 52:110-116

Liedtke W, Leman EE, Fyffe RE, Raine CS, and Schubart UK (2002) Stathmin-deficient mice develop an age-dependent axonopathy of the central and peripheral nervous systems. Am $J$ Pathol 160:469-480

Marklund U, Larsson N, Gradin HM, Brattsand G, and Gullberg M. (1996) Oncoprotein 18 is a phosphorylation-responsive regulator of microtubule dynamics. EMBO J 15:5290-5298 
Métin C, Deléglise D, Serafini T, Kennedy TE and Tessier-Lavigne M (1997) A role for netrin-1 in the guidance of cortical efferents. Dev 124:5063-5074

Miller MW (1987) The origin of corticospinal projection neurons in rat. Exp Brain Res 67:339351

Mizumura K, Takeda K, Hashimoto S, Horie T and Ichijo H (2006) Identification of Op18/stathmin as a potential target of ASK1-p38 MAP kinase cascade. J Cell Physiol 206:363370

Nagashima, M. (1994) Postnatal development of the rat corticospinal tract, with special reference to confocal laser scanning microscopy of growing axons. Neurosci. Res 19:81-92

Richards LJ, Koester SE, Tuttle R and O'Leary DD (1997) Directed growth of early cortical axons is influenced by a chemoattractant released from an intermediate target. $J$ Neurosci $17: 2445-2458$

Roos G, Brattsand G, Landberg G, Marklund U, and Gullberg M (1993) Expression of oncoprotein 18 in human leukemias and lymphomas. Leukemia 7:1538-1546

Sakai N and Kaprielian Z (2012) Guidance of longitudinally projecting axons in the developing central nervous system. Front Mol Neurosci 59:1-14

Schreyer DJ and Jones EG (1982) Growth and target finding by axons of the corticospinal tract in prenatal and postnatal rats. Neuroscience 7:1837-1853

Schreyer DJ and Jones EG (1988) Axon elimination in the developing corticospinal tract of the rat. Dev Brain Res 38:103-119 
Schubart UK, Yu J, Amat JA, Wang Z, Hoffmann MK, and Edelmann W (1996) Normal development of mice lacking metablastin (P19), a phosphoprotein implicated in cell cycle regulation. J. Biol. Chem. 271:14062-14066

Stanfield BB (1992) The development of the corticospinal projection. Prog Neurobiol 38:169202

Stein E and Tessier-Lavigne, M. (2001) Hierarchical organization of guidance receptros: silencing of netrin attraction by slit through a Robo/DCC receptor complex. Science 291:19281938

Stone MC, Rao K, Gheres KW, Kim S, Tao J, La Rochelle C, Folker CT, Sherwood NT, and Rolls MM (2012) Normal spastin gene dosage is specifically required for axon regeneration. Cell Rep 2:1340-1350

Tortoriello G, Morris CV, Alpar A, Fuzik J, Shirran SL, Calvigioni D, Keimpema E, Botting CH, Reinecke K, Herdegen T, Courtney M, Hurd YL, and Harkany T (2014) Miswiring the brain: delta 9-tetrahydrocannabinol disrupts cortical development by inducing an SCG10/stathmin-2 degradation pathway. EMBO J 33:668-685

Watabe-Uchida M, John KA, Janas JA, Newey SE, and Van Aelst L (2006) The Rac activator DOCK7 regulates neuronal polarity through local phosphorylation of stathmin/Op18. Neuron 51:727-739

Wiencken-Barger AE, Mavity-Hudson J, Bartsch U, Schachner M and Casagrande VA (2004) The role of L1 in axon pathfinding and fasciculation. Cereb Cortex 14:121-131

Yamada K, Matsuzaki S, Hattori T, Kuwahara R, Taniguchi M, Hashimoto H, Shintani N, Baba A, Kumamoto N, Yamada K, Yoshikawa T, Katayama T, and Tohyama M (2010) Increased stathmin 1 expression in the dentate gyrus of mice causes abnormal axonal arborizations. PLoS One 5, e8596. doi: 10.1371/journal.pone.0008596 
Yokoyama N, Romero MI, Cowan CA, Galvan P,Heimbacher F, Charnay P, Parada LF and Henkemeyer M (2001) Forward signaling mediated by Ephrin-B3 prevents contralateral corticospinal axons from recrossing the spinal cord midline. Neuron 29:85-97 


\section{Figure legends}

Figure 1: Diagram illustrating regions of the spinal cord used to identify temporally and spatially specific protein expression in the developing spinal cord.

(A) An unstained, bright field image of a cross section through the adult rat spinal cord illustrating the position (arrows) of the corticospinal tract (CST) in rats. (B) To detail protein expression in the CST as it develops, protein was extracted from the CST (red shaded area) at P0, P3, P14 and adult rats and analysed using iTRAQ. Note that, unlike the human corticospinal projection, the CST fibers in rats predominantly traverse the ventral segment of the dorsal column of the spinal cord. To compare spatial difference in protein expression in developing white matter tracts of the spinal cord, protein was extracted from the CST (red shaded area) of P3 rats, and compared to the proteins expressed in the lateral (green shaded area) and ventral (blue shaded area) white matter tracts of the same animals.

Figure 2: Western blot analysis verifies the differential expression of stathmin during development of the rat corticospinal tract.

Protein extracts were subjected to SDS-PAGE, transferred to nitrocellulose by electroblotting and probed with antibody against stathmin. After visualization using a chemiluminescent system, the integrated density of the bands was measured using ImageJ software (public domain program, National Institutes of Health, Bethesda, MD, USA, rsb.info.nih.gov/ij/). In order to overcome possible variability in density due to sample loading, stathmin/total protein ratios were calculated by integrated density measurement of the stathmin-immunoreactive bands on the blot and a horizontal slice of the gel (prior to western blotting), that was stained with Coomassie Blue (i.e. P0 = 0.94 (S.D. 0.35, P3 = 0.78 (S.D. 0.22), P14 = 0.10 (S.D. 0.04) and adult = 0.06 (S.D. 0.02).. Statistical significance of the differential expression was calculated using one-way analysis of variance (ANOVA) after logarithmic transformation of the data.** $=p$-value 0.001 to $<0.01$. Error bars represent standard deviation (S.D.).

Figure 3: Immunohistochemical staining of the postnatal rat cervical spinal cord reveals high levels of stathmin expression in the corticospinal tract (CST) during the developmental period.

At P0 stathmin staining initially appears in a very limited region (potentially representing the emerging CST) of the cervical cord, in the most ventral wedge of the dorsal columns (arrows). At P3 and P5 intense stathmin immunoreactivity appears restricted to the CST (arrows) with relatively low levels appearing in the surrounding grey matter or other white matter tracts. By P7 and P10 stathmin staining appears less intense in the CST than earlier developmental time points, though its expression was still only notable in the CST (arrows). By P14, stathmin staining was greatly reduced in the CST of the cervical cord, (arrow), and appeared to match that seen in all regions of the surrounding cord. Scale $=100 \mu \mathrm{m}$. 
Figure 4: Immunohistochemical staining of the fetal human brain reveals high levels of stathmin expression in the developing corticospinal system of humans.

(A) Cross section through the ventral portion of the human midbrain and brain stem, at $12^{\text {th }}$ gestational week (gw). Fine stathmin staining of the perpendicularly cut fibers passing through the medullary pyramidal tracts (arrows in A) are visible. (B) Similarly to A, a cross section through the fetal brain stem (at the level of pons and midbrain tegmentum) at $16^{\text {th }} \mathrm{gw}$ reveals fibrillary stathmin expression within the transpontine corticospinal (arrows) and other corticofugal fiber tracts. (C and D) Paramediosagittal section through the brain stem of the human telencephalon at $18^{\text {th }} \mathrm{gw}$ showing clear, heavy fibrillary staining of stathmin in the cerebral peduncules as well as the transpontine cortico-fugal tract (arrows in C and D) down to the level of the medullary pyramids.

Figure 5: Stathmin perturbation significantly affects neurite growth from embryonic rat cortical neurons grown in vitro.

(A) Immunohistochemical staining for beta III tubulin (green), stathmin (red) and DAPI (blue) of E17 rat cortical neurons grown in vehicle control containing media or $16 \mu \mathrm{M}$ of SB203580. While a number of long beta III tubulin+ processes were established by cells grown in vehicle control media, cells grown in the presence of high concentrations (16uM) of SB203580 showed short or no neurite growth. Stathmin immunoreactivity appeared relatively similar in both conditions, with obvious staining in the cell soma and finer staining in most neurites. Viewed at a higher magnification (shown on right), cells grown in control media appeared to establish long smooth neurite processes (arrows), while those established by cells grown in the presence of SB203580 appeared jagged, with many fine projections protruding off principle processes (arrowheads) (B) Counts of the average neurite length (in $\mu \mathrm{m}$ ) established by cells grown in control media, or in $1 \mu \mathrm{M}, 4 \mu \mathrm{M}, 16 \mu \mathrm{M}$ or $32 \mu \mathrm{M}$ of SB203580 (i.e. vehicle control $=37 \mu \mathrm{m}$ (S.E. 2.77), $1 \mu \mathrm{M}=43.81 \mu \mathrm{m}$ (S.E. 3.83), $4 \mu \mathrm{M}=35.38 \mu \mathrm{m}$ (S.E. 3.15), $16 \mu \mathrm{M}=8.21 \mu \mathrm{m}$ (S.E. 1.47) and $32 \mu \mathrm{M}=3.62 \mu \mathrm{m}$ (S.E. 1.23). ANOVA analysis revealed significant difference within the groups, and a post hoc Tukey's analysis indicated that cells treated with $16 \mu \mathrm{M}$ and $32 \mu \mathrm{M}$ SB203580 grew significantly shorter processes than cells in the control condition $(* * \mathrm{p}<0.01)$. There was no statistical difference in the neurite length of cells grown in control conditions in comparison to cells treated with either $1 \mu \mathrm{M}$ or $4 \mu \mathrm{M}$ of the drug. Error bars represent standard error (S.E.).

\section{Table Legends}

Table 1: Molecular and cellular functions of proteins that were increased in expression during development of the CST.

Ingenuity Pathway Analysis software (IPA) was used to assign molecular and cellular functional annotations to the proteins that were increased in expression at P0 and P3 compared to P14. The top five, significant (i.e. p-value $<0.05$ ), annotations are shown for each comparison. 
Table 2: Canonical pathways that were enriched in the up-regulated proteins during development of the CST: Ingenuity Pathway Analysis software (IPA) was used to determine the canonical pathways of proteins that were increased in expression at P0 and P3 compared to P14. The top five, significant (i.e. p-value $<0.05$ ), annotations are shown for each comparison. Ratio refers to the number of differentially expressed proteins that map to each pathway divided by the total number of proteins in the particular pathway. 